\title{
Actinobacillus equuli
}

National Cancer Institute

\section{Source}

National Cancer Institute. Actinobacillus equuli. NCI Thesaurus. Code C86099.

A species of anaerobic, Gram negative, rod shaped bacteria assigned to the phylum

Proteobacteria. This bacteria is nonmotile, oxidase and urease positive, weakly catalase positive, does not hydrolyze esculin and produces acid from glucose, lactose and xylose.

A. equuli is a commensal organism of the horse upper respiratory tract but may cause disease in foals and zoonotic infections in humans. 